\title{
Climate forcing reconstructions for use in PMIP simulations of the Last Millennium (v1.1)
}

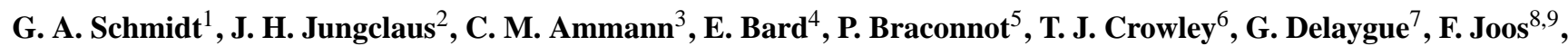 \\ N. A. Krivova ${ }^{10}$, R. Muscheler ${ }^{11}$, B. L. Otto-Bliesner ${ }^{3}$, J. Pongratz ${ }^{12}$, D. T. Shindell ${ }^{1}$, S. K. Solanki ${ }^{10,13}$, \\ F. Steinhilber ${ }^{14}$, and L. E. A. Vieira ${ }^{15}$ \\ ${ }^{1}$ NASA Goddard Institute for Space Studies and Center for Climate Systems Research, Columbia University, New York, USA \\ ${ }^{2}$ Max-Planck-Institute for Meteorology, Bundesstrasse 53, 20146 Hamburg, Germany \\ ${ }^{3}$ National Center for Atmospheric Research, 1850 Table Mesa Drive, Boulder, Colorado, USA \\ ${ }^{4}$ Université Aix-Marseille III/CNRS/IRD/Collège de France, CEREGE, Europôle de l'Arbois, BP 80, 13545 Aix-en-Provence \\ Cedex 04, France \\ ${ }^{5}$ Laboratoire des Sciences du Climat et de l'Environnement, Gif Sur Yvette, France \\ ${ }^{6}$ School of GeoSciences, University of Edinburgh, Edinburgh, UK \\ ${ }^{7}$ Université Joseph Fourier-Grenoble I/CNRS, LGGE, 54 rue Molière, St-Martin-d'Hères, France \\ ${ }^{8}$ Climate and Environmental Physics, Physics Institute, University of Bern, Sidlerstrasse 5, 3012 Bern, Switzerland \\ ${ }^{9}$ Oeschger Centre for Climate Change Research, University of Bern, 3012 Bern, Switzerland \\ ${ }^{10}$ Max-Planck-Institut für Sonnensystemforschung, 37191 Katlenburg-Lindau, Germany \\ ${ }^{11}$ Department of Earth and Ecosystem Sciences, Lund University, Sölvegatan 12, 22362 Lund, Sweden \\ ${ }^{12}$ Carnegie Institution of Washington, Department of Global Ecology, 260 Panama St., Stanford, CA 94305, USA \\ ${ }^{13}$ School of Space Research, Kyung Hee University, Yongin, Gyeonggi 446-701, Korea \\ ${ }^{14}$ Swiss Federal Institute of Aquatic Science and Technology, EAWAG, 8600 Dübendorf, Überlandstrasse 133, Switzerland \\ ${ }^{15}$ Laboratoire de Physique et Chimie de l'Environnement et de l'Espace and Université d'Orléans, 3A, Avenue de la \\ Recherche, 45071 Orléans cedex 2, France
}

Correspondence to: G. A. Schmidt (gavin.a.schmidt@ nasa.gov)

Received: 13 September 2011 - Published in Geosci. Model Dev. Discuss.: 23 September 2011

Revised: 22 December 2011 - Accepted: 13 January 2012 - Published: 30 January 2012

\begin{abstract}
We update the forcings for the PMIP3 experiments for the Last Millennium to include new assessments of historical land use changes and discuss new suggestions for calibrating solar activity proxies to total solar irradiance.
\end{abstract}

\section{Introduction}

Our previous paper (Schmidt et al., 2011) (hereafter v1.0) attempted to characterise the known forcings over the period $850 \mathrm{CE}$ to $1850 \mathrm{CE}$ (the Last Millennium or LM) for use in the Paleoclimate Model Intercomparison Project Phase III (PMIP3 http://pmip3.lsce.ipsl.fr/) simulations (Otto-Bliesner et al., 2009). Subsequent to its publication, a number of new reconstructions have been published, and this update aims to document the addition of these reconstructions to the PMIP3 database.
The first update is to include the Kaplan et al. (2011) reconstruction of land use and land cover changes. The second update is to discuss recent suggestions for the calibration of the grand solar minima in the solar proxy data to solar irradiance (Shapiro et al., 2011; Schrijver et al., 2011; Foukal et al., 2011). Finally, we update the Supplement to include these new reconstructions and correct a minor typographic error in the net radiative forcing file in the earlier version.

\section{Land Use/Land Cover (LULC) update}

Prior to the 20th century, most estimates of anthropogenic Land Use/Land Cover (LULC) changes are based on population estimates and assumptions about per capita land use combined with historical data (such as maps of agricultural areas). Kaplan et al. (2011) introduce the "Kaplan and 
Krumhardt 2010" LULC reconstruction (henceforth KK10) based on very different assumptions than the Pongratz et al. (2008) dataset (hereafter PEA) described in v1.0. Furthermore, the HYDE 3.1 database (Hurtt et al., 2009) has recently been extended back in time before 1500 (as far back as $12000 \mathrm{BP}$ ) (Klein Goldewijk et al., 2011).

Pongratz et al. (2008), Hurtt et al. (2009), and Klein Goldewijk et al. (2011) reconstruct agricultural area (pasture and cropland) and (in the PEA case) associated changes in natural forests, grasslands, and shrublands. These studies extend agricultural maps of the last few centuries back in time by calculating per-capita use of agricultural land. Calculations are done on a country-by-country basis, which takes into account differing per-capita use of agricultural land across regions (depending on local crop types, agrotechnology and on the importance of agriculture as compared to hunting, gathering, and fishing). Uncertainty estimates in these per-capita values can be estimated through time based on literature values to account for evolution of agrotechnology and changing fractions of population living in an agrarian system; the high and low estimates of the uncertainty range in Pongratz et al. (2008) account for these changes and their uncertainties in each region of the world, while in their mid-range scenario the per-capita land use is kept constant. By contrast, the KK10 dataset reconstructs changes in forest cover, by correlating population density and forest cover derived from literature values for 6 European countries for the last $3000 \mathrm{yr}$ (Kaplan et al., 2009). The European population densityforest cover relationship is then applied to the rest of the world, adjusted in the tropics for higher natural productivity of vegetation (Kaplan et al., 2011). All the reconstruction methods largely rely on the similar historical population estimates, however, strictly speaking the two approaches reconstruct different quantities. Being based on agricultural extent, the PEA and HYDE datasets reconstruct permanent changes in land cover, i.e. a change in vegetation type from natural forest, shrub and grassland to agriculture (cropland and pasture), and back again if agricultural area is abandoned. On the other hand, KK10 is based on forest cover data and thus can also include clearing of forest without a change in vegetation type (for instance, forest areas that are cleared for fuel and construction wood, mining, etc., without subsequent use for agriculture), that might have regrown.

Figure 1 shows the combined crops and pastures change in the KK10, PEA and extended HYDE 3.1 datasets. The KK10 data have been extended from 1850 to the present using a hybrid merge procedure with the HYDE data. For grid boxes where land clearance values intersect prior to 1850 , the HYDE data are used after the point of intersection, otherwise, a linear interpolation from the $1850 \mathrm{KK} 10$ value to the present day HYDE value is used (J. Kaplan, personal communication, 2011).

The differences between the reconstructions are quite large. Overall, anthropogenic land use changes are inferred to be much larger in the KK10 data and at earlier dates. At the

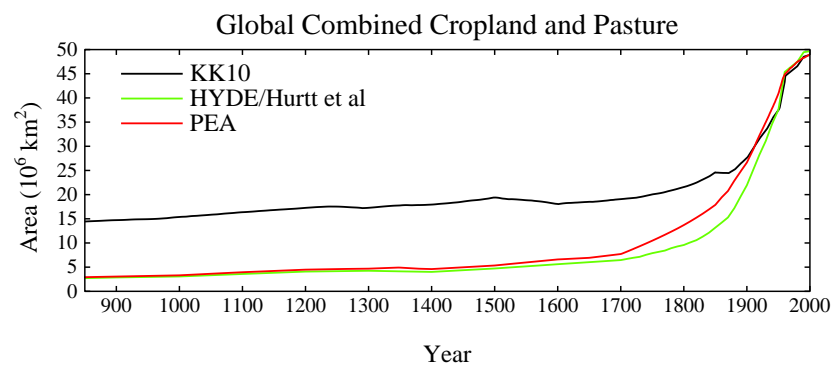

Fig. 1. Global combined cropland and pasture area in the "Kaplan and Krumhardt 2010" (KK10), Pongratz et al. (2008) (PEA) and the extended HYDE 3.1 (Hurtt et al., 2009; Klein Goldewijk et al., 2011) datasets.

regional scale, KK10 has significantly more pre-Colombian land clearance in the Americas, partly due to higher population estimates, although all land use reconstructions use population estimates that are in the mid range of the large range of literature estimates $(41,41$, and 60 million for PEA, HYDE/Hurtt, and KK10, respectively, in a literature range of 14-90 million; Pongratz et al., 2008; Krumhardt, 2010). However, the main reason for the difference is the assumption of significantly higher per-capita land use and therefore land use change in the KK10 dataset. In the PEA dataset, to account for the change in culture with the depopulation and colonization, the per-capita values derived from postColumbian times were replaced in pre-Columbian times by literature-based values of per-capita land use for indigenous Andean cultures, which show high land efficiency and therefore low land use per person. In the lowlands such as Amazonia per-capita land use is assumed even lower due to the importance of hunting, gathering, and fishing. Keeping recent per-capita values constant through time, HYDE shows somewhat larger agricultural areas and area changes with depopulation than PEA, but in both datasets the decrease in land use in the Americas is overwhelmed by increase elsewhere in the world, so does not show up as a reversal in the global upward trend of land use area as it does in KK10.

Differences between the datasets are thus mainly due to (1) similar, but not identical sources of population data; (2) the different assumptions on per-capita land use (constant prior to AD 1700 in PEA mid-range and in HYDE/Hurtt; changes in time based on literature values specific to each region in the world in the PEA uncertainty range; changes linked to population density based on literature values for Europe only in KK10); (3) and different reconstructed quantities (agricultural area as compared to forest cover). As is clear, the total amount of cleared land in KK10 is much larger than calculated by PEA and HYDE in the early centuries which has important implications for the amount of land-use related carbon emissions and surface albedo changes (see below). Note that KK10 does not explicitly distinguish between land cleared for crops or for pasture (unlike the other two 


\section{Total Solar Irradiance Reconstructions}

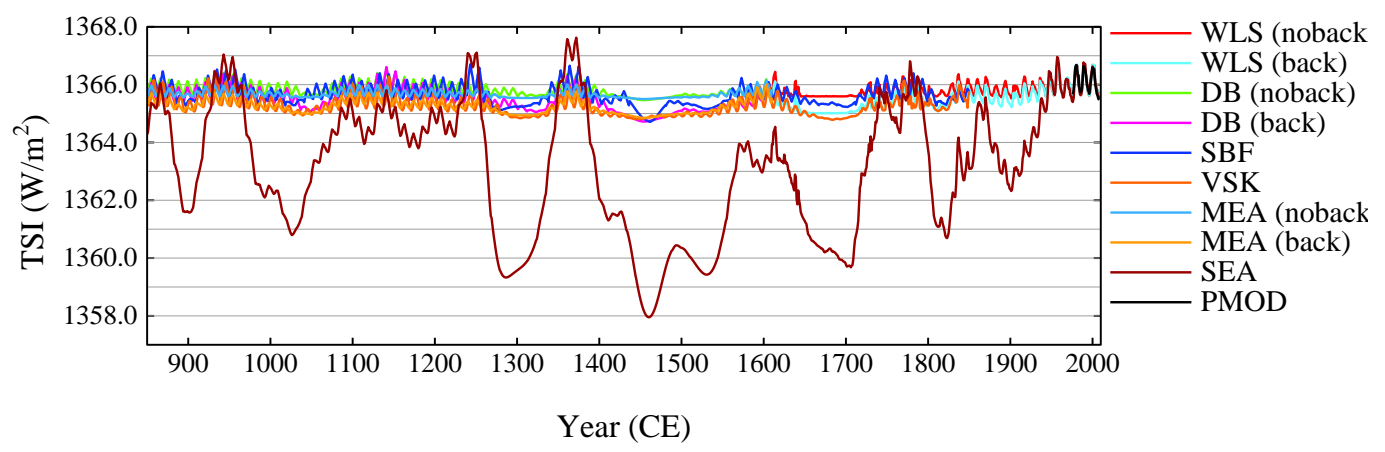

Fig. 2. Estimates of TSI including the SEA reconstruction calibrated to the WLS reconstructions over 1976-2006. Note: DB = Delaygue and Bard (2011), MEA = Muscheler et al. (2007), PMOD = Fröhlich (2009), SBF = Steinhilber et al. (2009), SEA = Shapiro et al. (2011), VSK $=$ Vieira et al. (2011), WLS $=$ Wang et al. (2005).

data sets - see Fig. 3 in v1.0). Implied carbon emissions are likely to be sensitive to this point (though this is less likely to impact surface albedo or roughness changes). Unfortunately, the differences between the datasets cannot be constrained by recourse to the atmospheric $\mathrm{CO}_{2}$ record due to uncertainties in long-term carbon uptake by the biosphere and oceans and responses of the carbon cycle to shorter term natural variability.

\section{Solar variations update}

We discussed the process of reconstructing a record of solar irradiance in v1.0 and noted that evaluation of the irradiance level during Grand Minima has been extremely difficult. Early reconstructions (i.e. Reid, 1997) used assumed solar-climate responses and temperature reconstructions to constrain the Total Solar Irradiance (TSI) change, but obviously this would be circular for PMIP purposes. The reconstructions suggested in Schmidt et al. (2011) were either physically based (VSK, WLS, SBF) or extrapolated from a physically based reconstruction (MEA, DB) (see caption of Fig. 2 for acronyms). Nonetheless, some assumptions concerning the "background" variation of irradiance (that which is not tied to the solar cycle) are inevitable.

Recently, there have been suggestions that the irradiance at the Grand Minima can be estimated by analogy: Schrijver et al. (2011) suggest that due to the seemingly exceptional character of the 2007-2009 solar minimum (compared to the two previous minima, Fröhlich, 2009), this level of activity is a good analog for the longer term minima. This would produce a reconstruction with minimal levels of background change and would be similar to the reconstructions provided previously. More strikingly, Shapiro et al. (2011) (henceforth SEA) have suggested that irradiance at low solar modulation function $(\Phi=0)$ should correspond to a solar disk that is uniformly as bright as the dimmest part of the solar disk at current 11-yr solar cycle minima (the "Model A" of Fontenla et al., 1999). This implies a reconstruction of irradiance that has an order of magnitude larger variance in amplitude than the reconstructions discussed by us previously.

It is important to note that the results of both these studies are mainly a function of their assumed calibration (given an estimate of the historical timeseries for $\Phi$ ). No independent evidence for these assumptions exists and no physically plausible model has been used. Note too that since "Model A" is poorly constrained in the lower photosphere, where most of the TSI changes originate, the uncertainty in the calculated TSI is high (Fontenla et al., 1999). In contrast to the SEA reconstruction, there is magnetic field evidence that supports only a modest increase of solar activity over the 20th century (Svalgaard and Cliver, 2010; Lockwood and Owens, 2011). Additionally, Foukal and Milano (2001) suggest that photometric evidence also rules out a strong decrease in the early 20th century, but the images they used are uncalibrated and so the results must be considered cautiously (Ermolli et al., 2009). For completeness, we have added the SEA reconstruction to the PMIP3 database. Processing the SEA data was done consistently with the other reconstructions. We use their reconstruction for TSI until 1610 CE. Subsequently, we use the 40-yr smoothed data from their "long" reconstruction combined with a synthetic 11-yr solar cycle (as discussed in Schmidt et al., 2011), though note that different approaches could also be used (e.g. Hathaway et al., 1994; Volobuev, 2009). The whole timeseries is calibrated to the WLS mean over 1976 to 2006 (Fig. 2). Note that the form of the variations pre-1610 are the same as in SBF (Steinhilber et al., 2009) since they use the same ${ }^{10} \mathrm{Be}$ record, but the scaling is very different.

In other recent work, Foukal et al. (2011) suggest that the link between TSI and facular indices is non-linear at low solar activity levels. This would imply a smaller TSI value during Grand minima than in the previously discussed reconstructions, while minimising recent trends. No 


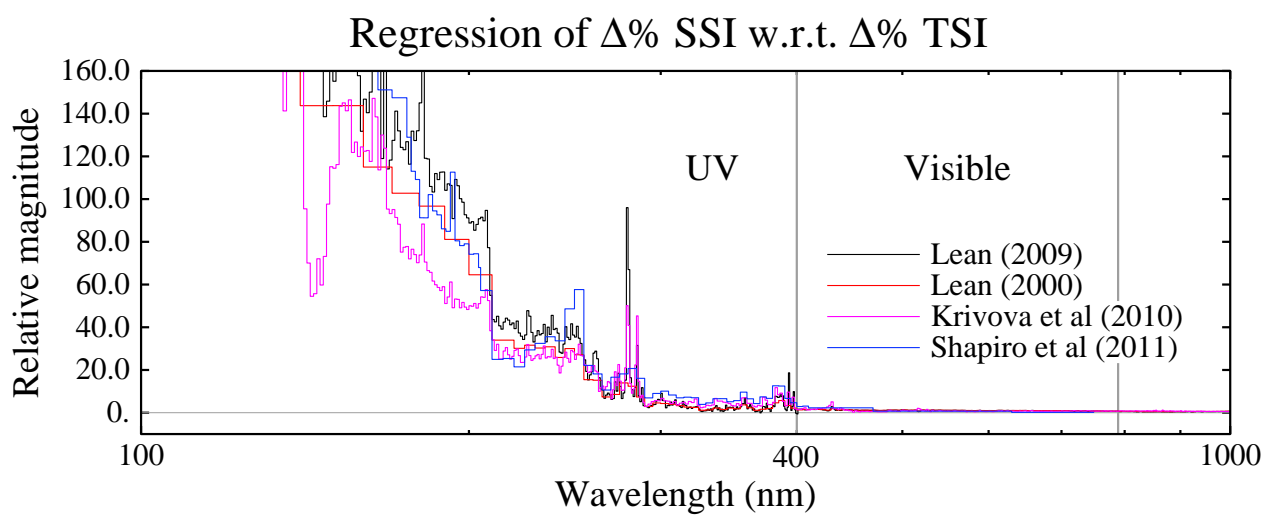

Fig. 3. Ratio of spectral irradiance variability to total solar irradiance variability from UV to Near IR. This shows the regression of the $\%$ change in solar spectral irradiance (SSI) at each wavelength to the \% change in TSI for 4 separate estimates (Lean, 2000, 2009; Krivova et al., 2010; Shapiro et al., 2011) (cf. Fig. 7 in Schmidt et al., 2011).

reconstructions yet exist that assess this evidence or use this assumption.

As indicated previously, the variations in solar spectral irradiance (SSI) have important consequences for the climate response (particularly in the stratosphere). Both Krivova et al. (2010) and Shapiro et al. (2011) provide independent measures of the irradiance over specific Ultra-Violet/Visible and Near Infra-Red bands. However, as should be clear from Fig. 3, the differences between these approaches and the Lean (2009) spectral irradiance changes are relatively small (though they differ by up to a factor of 2 in the UV). All the reconstructions we provide have identical SSI changes (as a function of TSI changes), based on the Lean (2009) data (thus the absolute changes in the UV scale with the absolute size of the changes in the TSI in each reconstruction). Note that very recent results (Haigh et al., 2010; Harder et al., 2009) suggest a radically different SSI change than we have assumed (much stronger in the UV, less or even the opposite sign in the visible range), but this depends to a large degree on an unconfirmed short time-series (2004-2007) from a single instrument on the SORCE mission (Lean and DeLand, 2012; Unruh et al., 2012). We therefore do not recommend the use of this SSI change in long term climate model experiments at this time.

Finally, we note that Kopp and Lean (2011) provide further strong evidence to indicate that recent measurements by the TIM instrument on board SORCE of around $1361 \mathrm{~W} \mathrm{~m}^{-2}$ are more reliable than the previously assumed $1366 \mathrm{~W} \mathrm{~m}^{-2}$. All of our solar reconstructions should be multiplied by a factor of 0.99634 if this solar baseline is used. Note, however, that models are mostly sensitive to the variations in irradiance, not to the baseline value, due to tuning for top-of-theatmosphere radiative balance in model control runs.

\section{Radiative forcing}

We now update the estimate we made of the radiative forcing associated with specific forcings. Note that as before, these are estimates, and that the actual forcing in any specific climate model may differ as a function of the model radiation code, background climate and implementation of the forcings.

For the KK10 LULC data, we make a rough estimate of the forcing due to surface albedo changes by calculating the instantaneous Top-of-Atmosphere radiative imbalance using GISS ModelE (Schmidt et al., 2006) once every hundred years (taking the average of calculations for 1 January and 1 July) and comparing it to a baseline period. As previously described in v1.0, these forcings are model dependent and do not include the impact of consequent carbon emissions, or the impact of changes in evapo-transpiration. The total late 20th century amount of crops and pastures is the same in the KK10, HYDE and PEA datasets, therefore the radiative forcing over the last millenium is determined by the magnitude of altered land cover in $850 \mathrm{CE}$. KK10 has a much larger early land cover change than the other datasets, and so has a smaller radiative forcing impact over the period being considered here. The net forcings in the Supplement are given with respect to pristine conditions which we derive using the forcing difference using (linearly interpolated) KK10 from any specific year to 2000, and then removing that from the near $2000 \mathrm{CE}$ forcing from pristine conditions taken from the Pongratz et al. (2009) data (actually, the 1992 value). The forcing from any other baseline (i.e. 850 $890 \mathrm{CE}$ or $1850 \mathrm{CE}$ ) can be calculated by simply subtracting the mean of those values over the new baseline period.

It is clear from Fig. 4 that the inclusion of the Shapiro et al. (2011) results makes the potential envelope of solar radiative forcing much larger than previously (cf. Fig. 9 in v1.0), which will undoubtedly lead to a greater response in model temperatures. Initial tests with a model of intermediate 


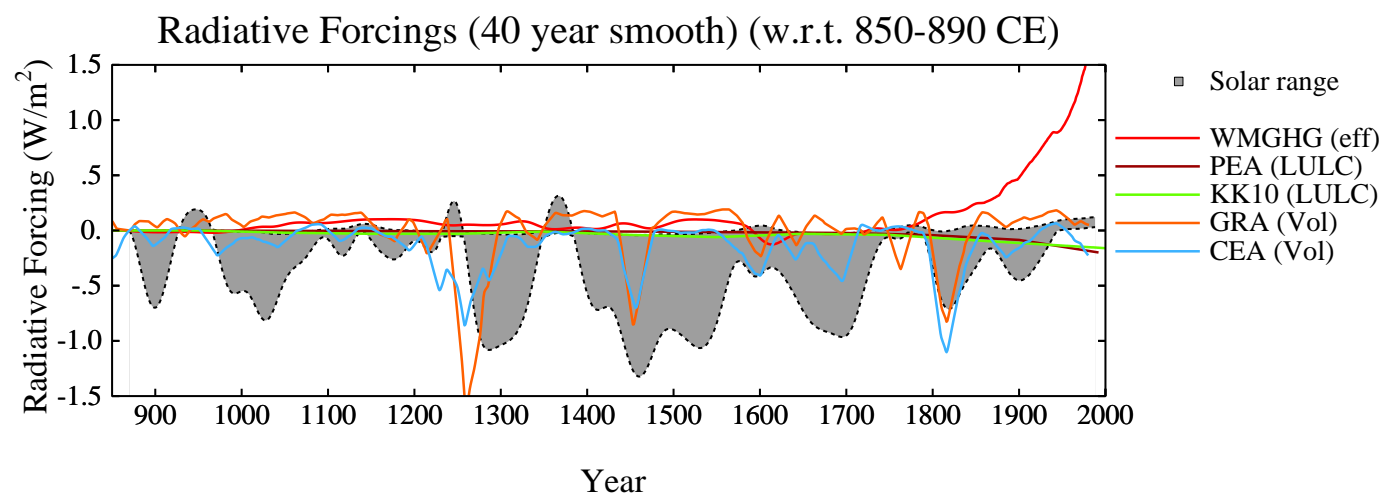

Fig. 4. Estimated radiative forcings for each driver (solar and volcanic forcings are smoothed using a $40 \mathrm{yr}$ triangular filter). WMGHG $=$ Well Mixed Greenhouse Gases; GRA = Gao et al. (2008); CEA = Crowley et al. (2008).

complexity show much greater variance in temperatures using SEA forcing, leading to a worse match to temperature reconstructions (Feulner, 2011). The differences in the LULC datasets are relatively small in this metric, but may be larger for regional responses.

Note that the version of the estimated net radiative forcing included in the v1.0 of this paper contained a minor typographical error (a small number of specific years in the land use section were duplicated). This has been fixed in v1.1.

\section{Discussion}

In order for the PMIP3 database of forcings for the Last Millennium to be as complete as possible, we have added new land use/land cover datasets and a new solar reconstruction to the available data. As in the previous iteration, we do not endorse one reconstruction over another, but present them as a range to give a sense of the structural uncertainty. Discussion will certainly continue in regard to the validity of various assumptions used in these reconstructions.

The SEA solar reconstruction diverges markedly from the other long-term solar reconstructions and from the WLS reconstruction that was recommended for the CMIP5 20th century simulations. At this stage however, prior to any discussion appearing in the literature, we feel that the use of this reconstruction as a sensitivity study in climate modelling should not be unnecessarily held up, and so we have added it to the PMIP3 database. We see no sensible way for Last Millennium simulations using SEA to merge smoothly with independent simulations started in 1850 and recommend therefore that any LM simulations using SEA be continued through the 20th century. Systematic differences in response to different reconstructions will hopefully be helpful in determining their realism (e.g. Feulner, 2011).

\section{Supplementary material related to this article is available online at: http://www.geosci-model-dev.net/5/185/2012/ gmd-5-185-2012-supplement.zip.}

Acknowledgements. All the reconstructions and the annual estimated radiative forcing are available in the Supplement or from https://pmip3.lsce.ipsl.fr/wiki/doku.php/pmip3:design:lm:final. We thank Ben Cook for help with the radiative forcing from the KK10 reconstruction, Alexander Shapiro, Jed Kaplan and Judith Lean for discussions, and two anonymous reviewers for helping improve the clarity of the paper.

Edited by: J. C. Hargreaves

\section{References}

Crowley, T. J., Zielinski, G., Vinther, B., Udisti, R., Kreutzs, K., Cole-Dai, J., and Castellano, E.: Volcanism and the Little Ice Age, PAGES Newsletter, 16, 22-23, 2008.

Delaygue, G. and Bard, E.: An Antarctic view of Beryllium-10 and solar activity for the past millennium, Clim. Dynam., 36, 22012218, doi:10.1007/s00382-010-0795-1, 2011.

Ermolli, I., Solanki, S. K., Tlatov, A. G., Krivova, N. A., Ulrich, R. K., and Singh, J.: Comparison among Ca II K spectroheliogram time series with an application to solar activity studies, Astroph. J., 698, 1000-1009, 2009.

Feulner, G.: Are the most recent estimates for Maunder Minimum solar irradiance in agreement with temperature reconstructions?, Geophys. Res. Lett., 38, L16706, doi:10.1029/2011GL048529, 2011.

Fontenla, J., White, O. R., Fox, P. A., Avrett, E. H., and Kurucz, R. L.: Calculation of Solar Irradiances, I. Synthesis of the Solar Spectrum, Astrophys. J., 518, 480-499, doi:10.1086/307258, 1999.

Foukal, P. and Milano, L.: A measurement of the quiet network contribution to solar irradiance variation, Geophys. Res. Lett., 28, 883-886, doi:10.1029/2000GL012072, 2001. 
Foukal, P., Ortiz, A., and Schnerr, R.: Dimming of the 17th century sun, Astrophys. J. Letts., 733, L38, doi:10.1088/20418205/733/2/L38, 2011.

Fröhlich, C.: Evidence of a long-term trend in total solar irradiance, Astron. Astroph., 501, L27-L30, doi:10.1051/00046361/200912318, 2009.

Gao, C. C., Robock, A., and Ammann, C.: Volcanic forcing of climate over the past 1500 years: An improved ice corebased index for climate models, J. Geophys. Res., 113, D23111, doi:10.1029/2008JD010239, 2008.

Haigh, J. D., Winning, A. R., Toumi, R., and Harder, J. W.: An influence of solar spectral variations on radiative forcing of climate, Nature, 467, 696-699, doi:10.1038/nature09426, 2010.

Harder, J. W., Fontenla, J. M., Pilewskie, P., Richard, E. C., and Woods, T. N.: Trends in solar spectral irradiance variability in the visible and infrared, Geophys. Res. Lett., 36, L07801, doi:10.1029/2008GL036797, 2009.

Hathaway, D., Wilson, R., and Reichmann, E.: The shape of the sunspot cycle, Solar Phys., 151, 177-190, doi:10.1007/BF00654090, 1994.

Hurtt, G. C., Chini, L. P., Frolking, S., Betts, R., Feedema, J., Fischer, G., Goldewijk, K. K., Hibbard, K., Janetos, A., Jones, C., Kindermann, G., Kinoshita, T., Riahi, K., Shevliakova, E., Smith, S., Stehfest, E., Thomson, A., Thorton, P., van Vuuren, D., and Wang, Y.: Harmonization of Global Land-Use Scenarios for the Period 1500-2100 for IPCC-AR5, Integrated Land Ecosystem-Atmosphere Processes Study (iLEAPS) Newsletter, 7, 6-8, 2009.

Kaplan, J. O., Krumhardt, K. M., and Zimmerman, N.: The prehistoric and preindustrial deforestation of Europe, Quat. Sci. Revs., 28, 3016-3034, 2009.

Kaplan, J. O., Krumhardt, K. M., Ellis, E. C., Ruddiman, W. F., Lemmen, C., and Klein Goldewijk, K.: Holocene carbon emissions as a result of anthropogenic land cover change, Holocene, 21, 775-791, doi:10.1177/0959683610386983, 2011.

Klein Goldewijk, K., Beusen, A., van Drecht, G., and de Vos, M.: The HYDE 3.1 spatially explicit database of human-induced global land-use change over the past 12,000 years, Global Ecol. Biogeogr., 20, 73-86, doi:10.1111/j.1466-8238.2010.00587.x, 2011.

Kopp, G. and Lean, J. L.: A new, lower value of total solar irradiance: Evidence and climate significance, Geophys. Res. Lett., 38, L01706, doi:10.1029/2010GL045777, 2011.

Krivova, N. A., Vieira, L. E. A., and Solanki, S. K.: Reconstruction of solar spectral irradiance since the Maunder Minimum, J. Geophys. Res., 115, A12112, doi:10.1029/2010JA015431, 2010.

Krumhardt, K. M.: Methodology for worldwide population estimates: $1000 \mathrm{BC}$ to 1850 , Tech. Rep. ARVE Technical Report 3, École Polytechnique Fédérale de Lausanne, Dept. of Environmental Engineering, ARVE Research Group, available at: http://ecospriv4.epfl.ch/pub/ARVE_tech_report3_pop_ methods_2010.pdf (last access: 16 January 2012), 2010.

Lean, J.: Evolution of the sun's spectral irradiance since the Maunder Minimum, Geophys. Res. Lett., 27, 2425-2428, 2000.

Lean, J.: Calculations of Solar Irradiance, available at: http://www.geo.fu-berlin.de/en/met/ag/strat/forschung/ SOLARIS/Input_data/Calculations_of_Solar_Irradiance.pdf (last access: 16 January 2012), 2009.

Lean, J. L. and DeLand, M. T.: How does the sun's spectrum vary?,
J. Climate, in press, 2012.

Lockwood, M. and Owens, M. J.: Centennial changes in the heliospheric magnetic field and open solar flux: The consensus view from geomagnetic data and cosmogenic isotopes and its implications, J. Geophys. Res., 116, A04109, doi:10.1029/2010JA016220, 2011.

Muscheler, R., Joos, F., Beer, J., Müller, S., Vonmoos, M., and Snowball, I.: Solar activity during the last $1000 \mathrm{yr}$ inferred from radionuclide records, Quat. Sci. Revs., 26, 82-97, doi:10.1016/j.quascirev.2006.07.012, 2007.

Otto-Bliesner, B. L., Joussaume, S., Braconnot, P., Harrison, S. P., and Abe-Ouchi, A.: Modeling and Data Syntheses of Past Climates, Eos Trans. AGU, doi:10.1029/2009EO110013, 2009.

Pongratz, J., Reick, C. H., Raddatz, T., and Claussen, M.: A reconstruction of global agricultural areas and land cover for the last millennium, Glob. Biogeochem. Cycles, 22, GB3018, doi:10.1029/2007GB003153, 2008.

Pongratz, J., Raddatz, T., Reick, C. H., Esch, M., and Claussen, M.: Radiative forcing from anthropogenic land cover change since A.D. 800, Geophys. Res. Lett., 36, L02709, doi:10.1029/2008GL036394, 2009.

Reid, G.: Solar forcing of global climate change since the mid-17th century, Climatic Change, 37, 391-405, 1997.

Schmidt, G. A., Ruedy, R., Hansen, J. E., Aleinov, I., Bell, N., Bauer, M., Bauer, S., Cairns, B., Canuto, V., Cheng, Y., Del Genio, A., Faluvegi, G., Friend, A. D., Hall, T. M., Hu, Y., Kelley, M., Kiang, N. Y., Koch, D., Lacis, A. A., Lerner, J., Lo, K. K., Miller, R. L., Nazarenko, L., Oinas, V., Perlwitz, J., Perlwitz, J., Rind, D., Romanou, A., Russell, G. L., Sato, M., Shindell, D. T., Stone, P. H., Sun, S., Tausnev, N., Thresher, D., and Yao, M.-S.: Present day atmospheric simulations using GISS ModelE: Comparison to in-situ, satellite and reanalysis data, J. Climate, 19, 153-192, doi:10.1175/JCLI3612.1, 2006.

Schmidt, G. A., Jungclaus, J. H., Ammann, C. M., Bard, E., Braconnot, P., Crowley, T. J., Delaygue, G., Joos, F., Krivova, N. A., Muscheler, R., Otto-Bliesner, B. L., Pongratz, J., Shindell, D. T., Solanki, S. K., Steinhilber, F., and Vieira, L. E. A.: Climate forcing reconstructions for use in PMIP simulations of the last millennium (v1.0), Geosci. Model Dev., 4, 33-45, doi:10.5194/gmd4-33-2011, 2011.

Schrijver, C. J., Livingston, W. C., Woods, T. N., and Mewaldt, R. A.: The minimal solar activity in 2008-2009 and its implications for long-term climate modeling, Geophys. Res. Lett., 38, L06701, doi:10.1029/2011GL046658, 2011.

Shapiro, A. I., Schmutz, W., Rozanov, E., Schoell, M., Haberreiter, M., Shapiro, A. V., and Nyeki, S.: A new approach to the long-term reconstruction of the solar irradiance leads to large historical solar forcing, Astron. Astrophys., 529, A67, doi:10.1051/0004-6361/201016173, 2011.

Steinhilber, F., Beer, J., and Fröhlich, C.: Total solar irradiance during the Holocene, Geophys. Res. Lett., 36, L19704, doi:10.1029/2009GL040142, 2009.

Svalgaard, L. and Cliver, E. W.: Heliospheric magnetic field 1835-2009, J. Geophys. Res., 115, A09111, doi:10.1029/2009JA015069, 2010.

Unruh, Y. C., Ball, W. T., and Krivova, N. A.: Solar Irradiance Models and measurements: a comparison in the $220 \mathrm{~nm}$ to 240 nm wavelength band, arXiv: 2011arXiv1111.2068U, 2012.

Vieira, L. E. A., Solanki, S. K., Krivova, N. A., and Usoskin, I.: 
Evolution of the solar irradiance during the Holocene, Astron. Astroph., 531, A6, doi:10.1051/0004-6361/201015843, 2011.

Volobuev, D.: The Shape of The Sunspot Cycle: A One-Parameter Fit, Solar Phys., 258, 319-330, doi:10.1007/s11207-009-9429-3, 2009.
Wang, Y., Cheng, H., Edwards, R. L., He, Y., Kong, X., An, Z., Wu, J., Kelly, M. J., Dykoski, C. A., and Li, X.: The Holocene Asian Monsoon: Links to Solar Changes and North Atlantic Climate, Science, 308, 854-857, 2005. 